\title{
Influence of AC System Fault on DC System Control \& Protection and Improvement Schemes
}

\author{
Yonghong TAO, Xia LEI, Qing TIAN, and Huali XU
}

\begin{abstract}
There are twelve high voltage direct current (HVDC) transmission projects in China Southern Power Grid. If the inverter alternating current (AC) system fault leads to HVDC protection system maloperation, it's harm to the safe and reliable operation of the system. To solve the above problem, firstly, this paper selects the possible maloperation DC protection functions on AC faults according to RTDS (Real Time Digital System) test. Then influence of AC fault on DC control protection is analyzed. Combined with the test and principle analysis, the improved idea of using AC system side protection to remove faults and avoid DC protection maloperation or blocking is put forward. It is suggested that the DC protection delay setting should be adjusted and matched with the AC protection setting within the main equipment tolerance, and the corresponding scheme of DC protection optimization is given. Finally, the simulation tests were carried out by the RTDS based on 7 HVDC current projects, and the improved protection schemes were verified. The improved protection schemes have been put into effect in China Southern Power Grid HVDC projects. The operation experience shows that these schemes can effectively avoid the shutdown risk of HVDC system caused by AC system fault.
\end{abstract}

Index Terms - AC system fault, control \& protection, coordination of protection, DC blocking, equipment tolerance, HVDC protection, system fault.

\section{INTRODUCTION}

$\mathrm{T}$ HERE were twelve HVDC projects feed in Guangdong power grid by 2020. "Strong DC \& weak AC" characteristic is more obvious [1]-[2]. The smaller the electrical distance between HVDC landings is, the more important the interaction between $\mathrm{AC}$ and DC system is [3]-[4]. So the corresponding measures must be taken.

The operating experience shows that under the $\mathrm{AC}$ fault, the HVDC emergency switch off may be activated causing multiple HVDC projects power reduction or blocking, such as “2016.09.12 Chu Sui”, "2016.12.15 Gao zhao", all 5 HVDC

Manuscript received March 9, 2021; revised April 25 and May 24, 2021; accepted May 27, 2021. Date of publication June 30, 2021; date of current version June 17, 2021. This work was supported by the National Natural Science Foundation of China under Grant 61973257. This paper was presented in part at the 4th International Conference on HVDC (HVDC 2020), Xi' an, China, September 2020.

Y. Tao and X. Lei are with School of Electrical and Electronic Information, Xihua University, Chengdu, China (e-mail: 79186321@qq.com; 274757067@qq.com).

Q. Tian is with Power Dispatching Center, China Southern Power Grid, Guangzhou, China (e-mail: 6196440@qq.com).

H. Xu is with China United Engineering Corporation Limited, Hangzhou, China (e-mail: xuhl@chinacuc.com).

Digital Object Identifier 10.24295/CPSSTPEA.2021.00014 commutation failures occurred in China Southern Power Grid [5]-[9]. There are more multiple HVDC commutation failures, like 12 times in 2020, with more HVDC in China Southern Power Grid.

At present, the HVDC protection settings are mainly given by manufacturer and verified by Real Time Digital Simulation RTDS [10]-[13]. In order to protect the main equipment, some HVDC protections settings, with low threshold or short time delay, are very sensitive, leaving the equipment tolerance not fully used. Some HVDC valve area protections, such as Converter AC Differential Protection (87CBY, 87CBD), Converter DC Differential Protection (87CG), with low threshold or short time delay, are not coordinated with AC protection and may mistrip with long time $\mathrm{AC}$ fault. The setting scheme RTDS, limited by the simulation scale, time and personnel, tends to check the conventional operation mode and the short time fault. The complexity operations of actual AC and DC large system, such as continuous AC system failure and complex harmonic environment, are not fully considered.

The maloperations of the existing DC protection caused by AC fault are analyzed [14], but the setting principle of HVDC protection is not given clearly, nor the coordination between DC protection and AC protection are considered fully. The protection of a large HVDC network, consisting of the system level, fault detection and coordination with the operation of $\mathrm{AC}$ system, is still a big challenge [15].

In case of AC system side fault, DC control and protection system should keep DC transmission system running smoothly and avoid DC blocking. Therefore, it is necessary to study the cooperation of AC and DC control and protection system, and optimize the DC protection schemes that may trip during the AC fault.

This paper analyzes the actual fault waveforms and simulation tests, studies the DC protection setting principles in AC-DC hybrid operation power grid, gives the DC protection setting principles which are compatible with $\mathrm{AC}$ system fault clearing time and $\mathrm{DC}$ main equipment tolerance.

\section{Analysis of DC System Protection Characteristics UNDER AC FAULTS}

\section{A. RTDS Test Analysis}

The RTDS test system based on 7 HVDC (Gui-guang 1, 2, Tian-guang, Chu-sui, Niu-cong, Pu-qiao, Jing-zhong) was utilized to analyze the HVDC response characteristics and 
TABLE I

THe INVERTER SiDE TRIP SEQuences

\begin{tabular}{|c|c|c|c|c|c|c|}
\hline \multirow{2}{*}{ No. } & \multicolumn{2}{|c|}{ Case 1} & \multicolumn{2}{|r|}{ Case 2} & \multicolumn{2}{|r|}{ Case 3} \\
\hline & Relative time (ms) & Incident & Relative time (ms) & Incident & Relative time (ms) & Incident \\
\hline 1 & zero & commutation failure & zero & commutation failure & zero & commutation failure \\
\hline 2 & 1280 & $\begin{array}{l}\text { pole } 1 \text { low valve group } \\
\text { 87CBY Stage } 2 \text { trip }\end{array}$ & 1600 & $\begin{array}{l}\text { pole } 1 \text { low valve group } \\
87 \mathrm{CBY} \text { Stage } 2 \text { trip }\end{array}$ & 759 & $\begin{array}{l}\text { pole } 1 \text { low valve group } \\
\text { 87CG Stage } 1 \text { trip }\end{array}$ \\
\hline 3 & 1295 & $\begin{array}{l}\text { pole } 1 \text { high valve group } \\
\text { 87CBY Stage } 2 \text { trip }\end{array}$ & 1600 & $\begin{array}{l}\text { pole } 1 \text { high valve group } \\
87 \mathrm{CBY} \text { Stage } 2 \text { trip }\end{array}$ & 760 & $\begin{array}{l}\text { pole } 1 \text { high valve group } \\
\text { 87CG Stage } 1 \text { trip }\end{array}$ \\
\hline 4 & 1604 & $\begin{array}{l}\text { pole } 2 \text { low valve group } \\
27 D C \text { Stage } 1 \text { trip }\end{array}$ & 1700 & $\begin{array}{l}\text { pole } 1 \text { low valve group } \\
87 \text { CG Stage } 1 \text { trip }\end{array}$ & 1041 & $\begin{array}{l}\text { other station blocking signal } \\
\text { (rectifier side 27DC trip) }\end{array}$ \\
\hline 5 & - & - & 1800 & $\begin{array}{l}\text { pole } 1 \text { high valve group } \\
\text { 87CG Stage } 1 \text { trip }\end{array}$ & 3009 & $\begin{array}{l}\text { pole } 1 \text { both valve group } \\
27 D C \text { Stage } 2 \text { trip }\end{array}$ \\
\hline 6 & - & - & 3398 & pole $2100 \mathrm{~Hz}$ protection trip & 3025 & $\begin{array}{l}\text { No AC filter available } \\
\text { (power reduction) }\end{array}$ \\
\hline 7 & - & - & 3449 & pole $1100 \mathrm{~Hz}$ protection trip & 4023 & $\begin{array}{l}\text { pole } 1 \text { both valve group } \\
27 \mathrm{AC} \text { trip }\end{array}$ \\
\hline
\end{tabular}

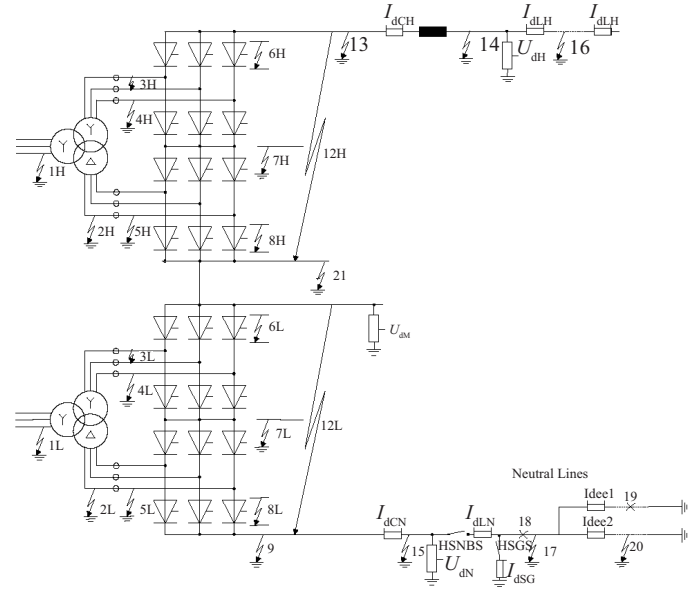

Fig. 1. Schematic diagram of DC protection measuring device location and fault points.

protection action characteristics under AC system faults (fault point 1), as shown in Fig. 1. The protection actions and the cooperation relationship were studied when the DC protections trip and pole control emergency shutdown were disabled.

The RTDS platform used in this article is based on the real structure which has 7 HVDC projects connected by a largescale AC system. The DC primary system and its connected external AC system are simulated in the RTDS. The RTDS system provides the actual DC control \& protection devices with the required voltage, current and tap changer, et al. through the GT series interface board and power amplifier. The protection device returns the trip or alarm signals to the RTDS to form a real-time closed-loop test system.

Initial state before failure: the rated voltage of the DC system is $\pm 800 \mathrm{kV}$, the rated current is $3.125 \mathrm{kA}$, and the length of the DC line is $1413 \mathrm{~km}$. Rectifier side AC system impedance $8.66 \Omega$, the inverter side AC system impedance $5.11 \Omega$. HVDC bipolar operation, four valve group, rated power $5000 \mathrm{MW}$, equivalent $\mathrm{AC}$ systems on both sides using large short circuit capacity. The fault times were all set to 5 seconds for singlephase to ground fault (case 1), phase to phase fault (case 2), and three-phase fault (case 3). The schematic diagram of the test system is shown in Fig. 1.

The inverter side trip sequences in the above cases, taking the commutation failure as starting point, were shown in Table I.

\section{1) Converter AC Differential Protection ( $87 C B Y, 87 C B D)$}

Evaluation Principle: $I_{\mathrm{ac}}-I_{\mathrm{acD}}>\Delta, I_{\mathrm{ac}}-I_{\mathrm{acY}}>\Delta, I_{\mathrm{ac}}=\max$ $\left(I_{\text {acY }}, I_{\text {acD }}\right), I_{\text {acY }}, I_{\text {acD }}$ are converter transformer secondary side, wye currents and delta currents.

Protection has 2 stages: Stage 1 must react on continuous commutation failures for high load conditions Stage 2 must react on continuous commutation failures slower than redundancy switchover in Pole Control (200 ms); Stage 2 must not react on 1 phase $\mathrm{AC}$ faults.

\section{2) Converter DC Differential Protection ( $87 C G)$}

Evaluation Principle: $I_{\mathrm{D}}-I_{\mathrm{acY}}>\Delta, I_{\mathrm{D}}-I_{\mathrm{acD}}>\Delta, I_{\mathrm{D}}$ is DC current converter high voltage side.

Protection has 2 stages: Stage 1 must react on converter DC faults that are bypassing the inverter and continuous commutation failures for high load conditions; Stage 2 must react on converter DC faults that are bypassing the inverter slower than redundancy switchover in Pole Control (200 ms); Stage 2 must not react on 1 phase AC faults. The protection function is blocked during bypass operation at the rectifier.

\section{3) $100 \mathrm{~Hz}$ Detection}

Evaluation Principle: $I_{\mathrm{dL}} 100>\Delta, I_{\mathrm{dL}} 100$ is the $100 \mathrm{~Hz}$ component of the DC current line high voltage side.

\section{4) AC Undervoltage Protection (27AC)}

Evaluation Principle: $U_{\text {ac }}<\Delta, U_{\text {ac }}$ is minimum voltage of converter transformer valve side three-phase voltages.

\section{5) DC Undervoltage Protection (27DC)}

Evaluation Principle: $\left|U_{\mathrm{dL}}\right|<\Delta$ for single 12 pulse converter; $\Delta 2<\left|U_{\mathrm{dL}}\right|<\Delta 1$ (Stage 1), $\left|U_{\mathrm{dL}}\right|<\Delta$ (Stage 1) for double 12 pulse converter; $U_{\mathrm{dL}}$ is the $\mathrm{DC}$ voltage line high voltage side.

After all the protection values and tests are analyzed, it can 

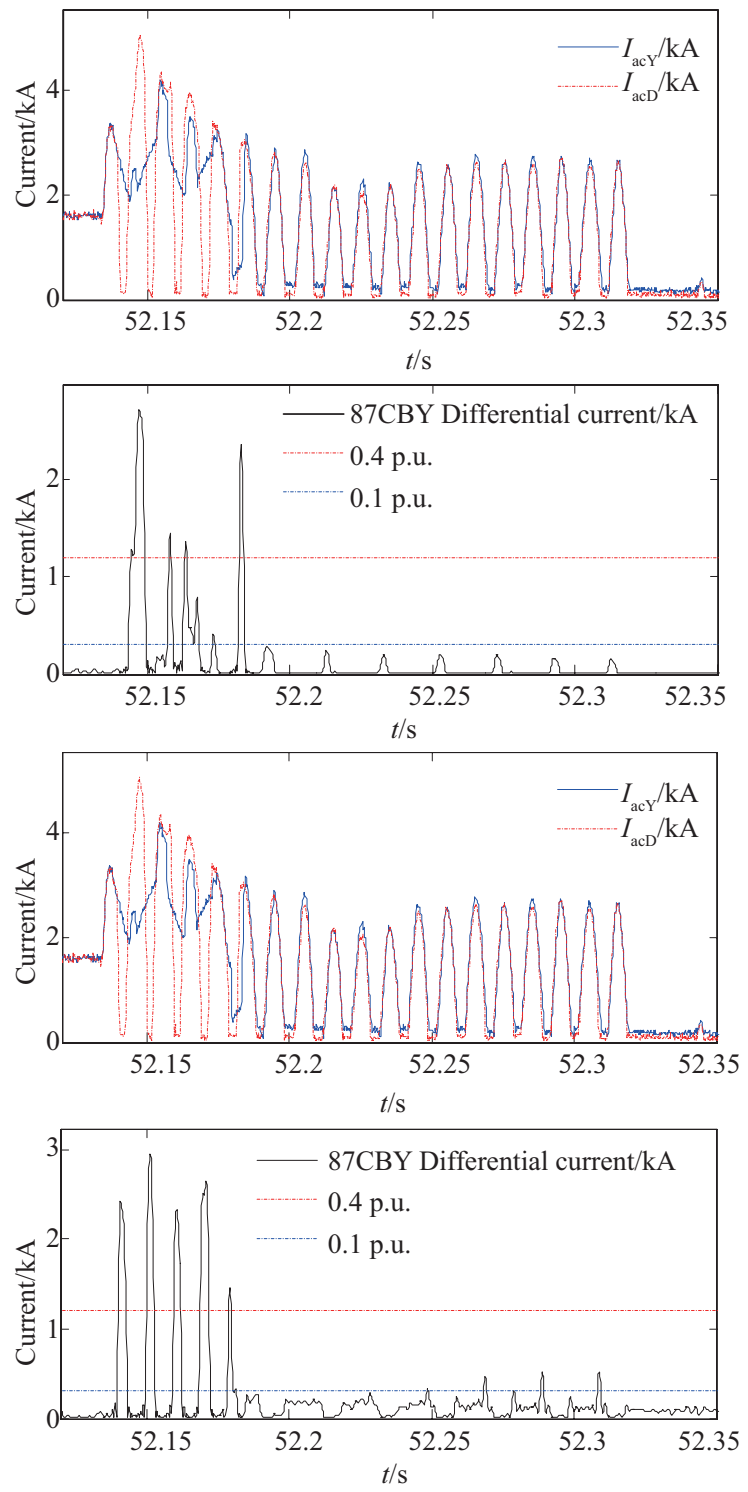

Fig. 2. The $87 \mathrm{CBY}, 87 \mathrm{CBD}$ protection analysis of Zhaoqing station pole 1 .

be seen that when the $\mathrm{AC}$ system is disturbed for a long time, the $\mathrm{AC}$ and DC voltage decreases significantly, the DC current decreases, and the triggering angle increases. The possible protection actions include: $87 \mathrm{CBY}, 87 \mathrm{CBD}$ Protection Section II, $87 \mathrm{CG}$ protection Section I, $50 \mathrm{~Hz}$ protection, $100 \mathrm{~Hz}$ protection, AC Undervoltage Protection (27AC), DC Undervoltage Protection (27DC), and commutative failure protection.

\section{B. Differential Current Analysis of Typical Cases}

On 15th Dec., 2016, AB phases fault occurred in $500 \mathrm{kV}$ power line which was near Zhaoqing station (inverter side of Guizhou-Guangdong HVDC) and Suidong station (inverter side of Yunnan-Guandong HVDC). Both pole 1 and pole 2 HVDC line protection tripped and lines are forced retarded successfully. Commutation failure occurred in the above two HVDC projects. AC fault lasted about $270 \mathrm{~ms}$. To solve the practical engineering problems, the differential current of
TABLE II

ANALYSIS OF 87CBY AND 87CBD Duty CyCle (\%)

\begin{tabular}{lccccc}
\hline \hline Recorder & $\begin{array}{c}\text { Protection and } \\
\text { threshold }\end{array}$ & $50 \mathrm{~ms}$ & $100 \mathrm{~ms}$ & $150 \mathrm{~ms}$ & $200 \mathrm{~ms}$ \\
\hline & $87 \mathrm{CBY} / 0.07$ p.u. & 43.12 & 22.96 & 15.31 & 11.48 \\
duty & $87 \mathrm{CBY} / 0.4$ p.u. & 15.62 & 7.81 & 5.21 & 3.91 \\
cycles & $87 \mathrm{CBD} / 0.07$ p.u. & 44.68 & 24.53 & 20.52 & 16.71 \\
& $87 \mathrm{CBD} / 0.4$ p.u. & 24.06 & 12.03 & 8.02 & 6.02 \\
\hline \hline
\end{tabular}

87CBY, 87CBD and other protections are analyzed based on transient fault recorder. The possible maloperation DC protections are given accordingly.

\section{1) $87 C B Y, 87 C B D$ Protection Analysis}

The $87 \mathrm{CBY}$ and $87 \mathrm{CBD}$ protection analysis of Zhaoqing station pole 1 is shown in Fig. 2. 87CBY/87CBD protection has discontinuous differential current under $\mathrm{AC}$ system fault. When the integral feature is adopted, $87 \mathrm{CBY}$ and $87 \mathrm{CBD}$ may mistrip.

Siemens protection technical route adopts the integral characteristic, and the return speed is about $1 / 20$ of the integral speed when the criterion isn't met; Nari technical route returns the protection when the criterion isn't met within short delay.

The concept of duty cycle in telecommunication field is used to explain the characteristics of discontinuous differential current. Duty cycle refers to the ratio of the positive pulse time to the total pulse time in an ideal pulse sequence (such as square wave). The differential current duty cycle in this paper refers to the ratio of effective differential current time to fault time. Effective differential current is the differential current that is greater than the protection threshold.

If the fault duration is $T$, the differential current time that meets and does not meet the protection threshold is $T_{1}, T_{2}$ respectively. $T=T_{1}+T_{2}$, then the duty cycle $d=T_{1} / T$.

When threshold is set as 0.07 p.u. (stage 2) and 0.4 p.u. (stage 1) respectively, the Zhaoqing station pole $187 \mathrm{CBY}$ and $87 \mathrm{CBD}$ differential current duty cycles are shown in Table II calculated in $50 \mathrm{~ms}, 100 \mathrm{~ms}, 150 \mathrm{~ms}, 200 \mathrm{~ms}$ fault recorder data.

\section{2) $87 C G$ Protection Analysis}

$87 \mathrm{CG}$ protection analysis of Zhaoqing station pole 1 is shown in Fig. 3. 87CG protection has discontinuous differential current in case of AC system fault. When the integration is adopted, there is maloperation possibility.

When threshold is set as 0.07 p.u. (stage 2) and 0.5 p.u. (stage 1) respectively, the Zhaoqing station pole $187 \mathrm{CG}$ differential current duty cycles are shown in Table III calculated in $50 \mathrm{~ms}$, $100 \mathrm{~ms}, 150 \mathrm{~ms}, 200 \mathrm{~ms}$ fault recorder data.

\section{3) $50 \mathrm{~Hz}, 100 \mathrm{~Hz}$ Detection Analysis}

$50 \mathrm{~Hz}, 100 \mathrm{~Hz}$ detection analysis of Zhaoqing station pole 1 is shown in Fig. 4. When threshold is set as 0.03 p.u., the Zhaoqing station pole $150 \mathrm{~Hz}$ and $100 \mathrm{~Hz}$ differential current duty cycles are shown in Table IV calculated in $50 \mathrm{~ms}, 100 \mathrm{~ms}$, $150 \mathrm{~ms}, 200 \mathrm{~ms}$ fault recorder data. 

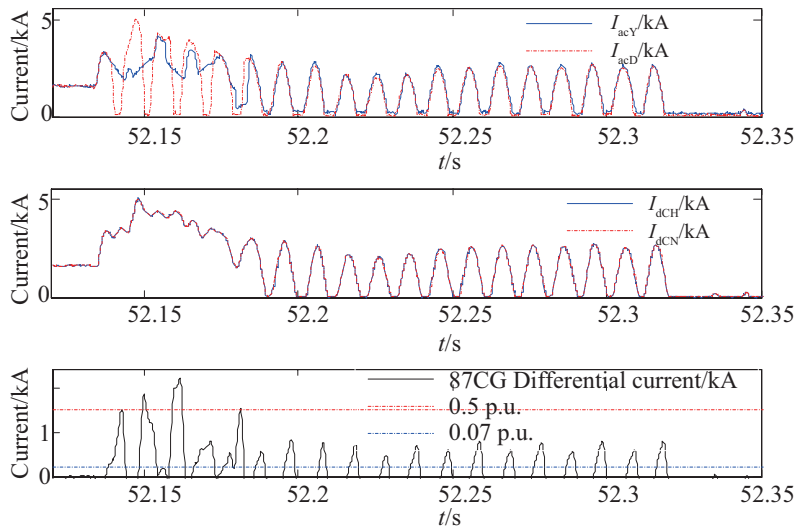

Fig. 3. The $87 \mathrm{CG}$ protection analysis of Zhaoqing station pole 1 .

TABLE III

ANALYSIS OF 87CG Duty CyCLE (\%)

\begin{tabular}{lccccc}
\hline Recorder & Protection and threshold & $50 \mathrm{~ms}$ & $100 \mathrm{~ms}$ & $150 \mathrm{~ms}$ & $200 \mathrm{~ms}$ \\
\hline duty & $87 \mathrm{CG}(0.07$ p.u. $)$ & 63.75 & 45.46 & 40.20 & 35.85 \\
cycles & $87 \mathrm{CG}(0.5$ p.u. $)$ & 11.25 & 5.62 & 3.75 & 2.81 \\
\hline
\end{tabular}

During the initial and recovery period of AC fault, both the $50 \mathrm{~Hz}$ component and the $100 \mathrm{~Hz}$ component are included in the DC current. The $100 \mathrm{~Hz}$ component in the DC side is stable when the AC unsymmetrical fault occurs.

During the initial and recovery of $\mathrm{AC}$ fault, there is $50 \mathrm{~Hz}$ component in the $\mathrm{DC}$ current, but the attenuation is very fast.

According to the commutation principle, the 2 nd harmonic in $\mathrm{AC}$ system will cause the $50 \mathrm{~Hz}$ component in the DC system. When the fault electrical distance is close to the HVDC system, the $100 \mathrm{~Hz}$ component will reach the threshold, and the $50 \mathrm{~Hz}$ component will approach the threshold.

After the TianGuang HVDC bipolar blocking accident, the time delay of $100 \mathrm{~Hz}$ protections for each HVDC projects were improved. At present, the all HVDC projects $100 \mathrm{~Hz}$ protection settings are modified as follows: Stage 1 is disabled, Stage 2 time delays are all extended to 3 seconds.

\section{4) $27 \mathrm{AC}$ and $27 \mathrm{DC}$ Protection Analysis}

$50 \mathrm{~Hz}, 100 \mathrm{~Hz}$ detection analysis of Zhaoqing station pole 1 is shown in Fig. 5. When threshold is set as 0.2 p.u., the Zhaoqing station pole $127 \mathrm{AC}$ and 27DC differential current duty cycles are shown in Table V calculated in $50 \mathrm{~ms}, 100 \mathrm{~ms}$, $150 \mathrm{~ms}, 200 \mathrm{~ms}$ fault recorder data.

During the AC fault, the 27AC or 27DC protection may trip according to the fault condition and the electrical distance from the converter station.

\section{The Effect of AC Fault on DC Control/Protection \\ 1) Effect on Control Function}

The zero current monitoring, AC low voltage monitoring, large trigger angle in the pole control (group control) may be affected, but the time delay for above function is big enough;
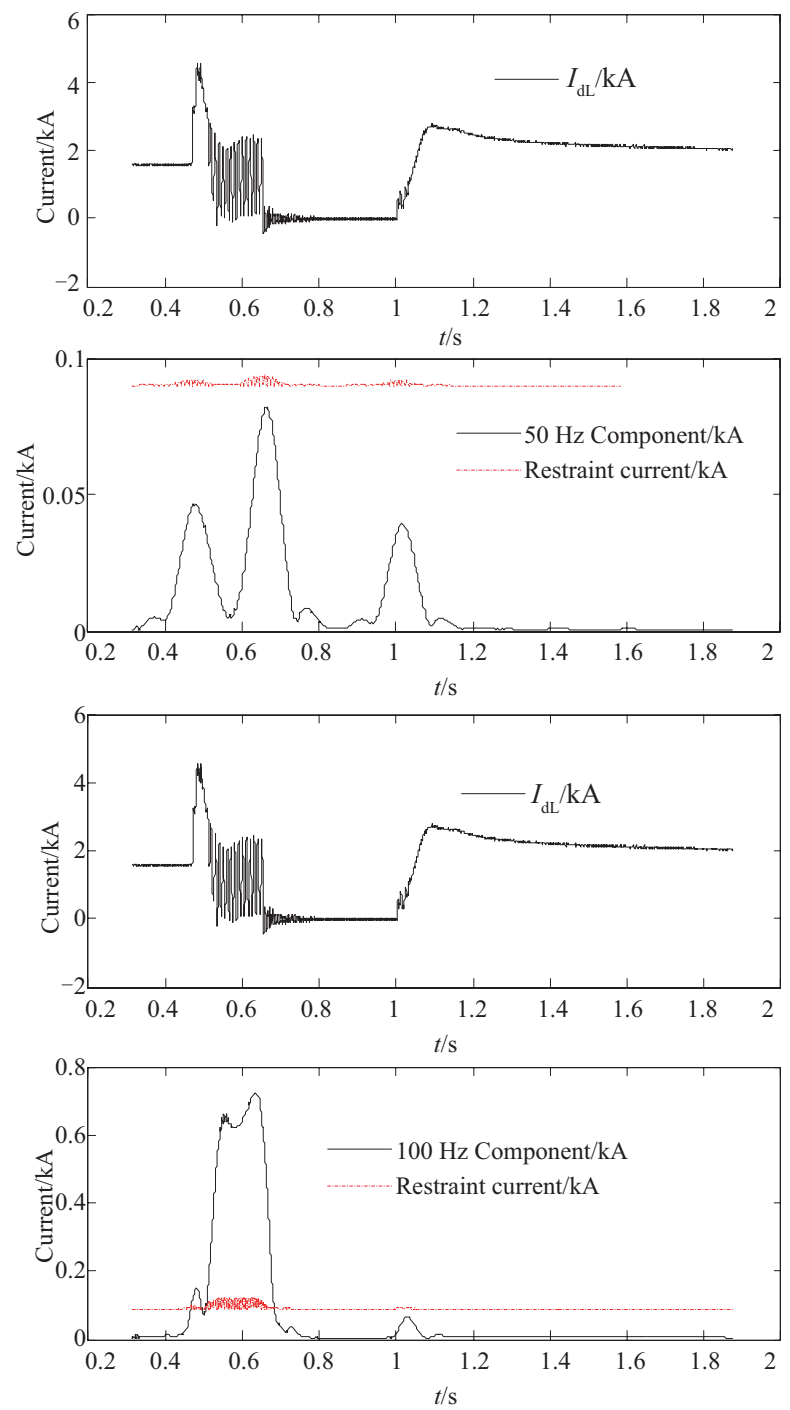

Fig. 4. The $50 \mathrm{~Hz}$ and $100 \mathrm{~Hz}$ detection analysis of Zhaoqing station pole 1 .

TABLE IV

ANALYSIS OF 50 AND $100 \mathrm{~Hz}$ Duty CyCle (\%)

\begin{tabular}{lccccc}
\hline Recorder & Protection and threshold & $50 \mathrm{~ms}$ & $100 \mathrm{~ms}$ & $150 \mathrm{~ms}$ & $200 \mathrm{~ms}$ \\
\hline duty & $50 \mathrm{~Hz}(0.03$ p.u. $)$ & 0 & 0 & 0 & 0 \\
cycles & $100 \mathrm{~Hz}(0.03$ p.u. $)$ & 74.37 & 87.18 & 91.45 & 93.59 \\
\hline
\end{tabular}

When the $\mathrm{AC}$ voltage is too low, the valve trigger may be affected. But in this case, the trip function will be blocked automatically;

Last breaker/line in AC/DC station control is not affected.

\section{2) Effect on Valve Cool}

The AC power supply and the main pump will be affected. The AC power switch, motor fault and other auxiliary protection may trip, but the trip time delay for AC power switch failure and no pump operation is bigger than $3.1 \mathrm{~s}$.

\section{3) Effect on Other Protections}

The $100 \mathrm{~Hz}$ component in the DC side has no influence on 


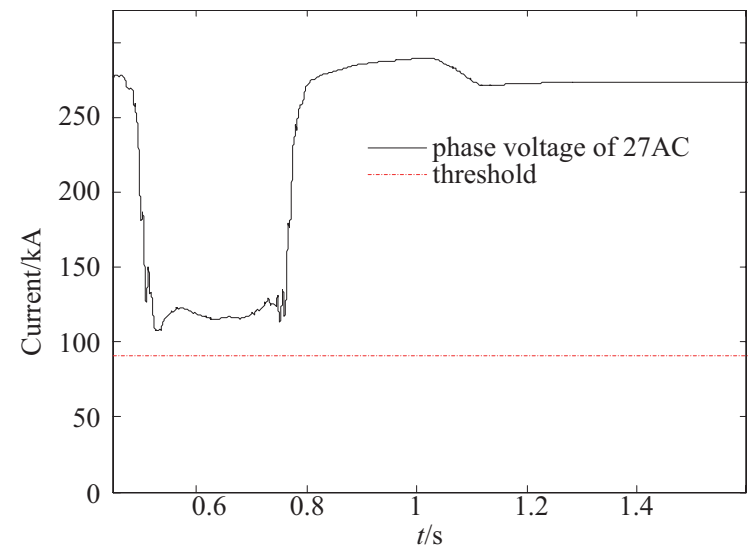

(a)

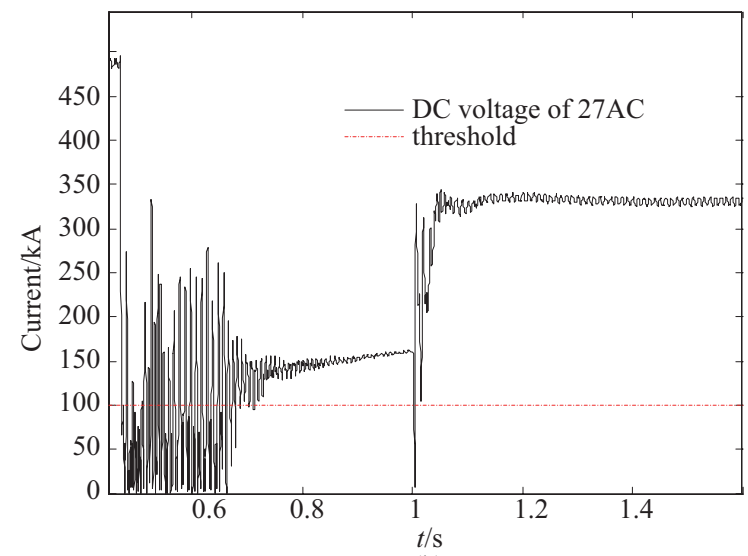

(b)

Fig. 5. The 27AC and 27DC protection analysis of Zhaoqing station pole1.

TABLE V

ANALYSIS OF 27DC Duty CyCle (\%)

\begin{tabular}{lccccc}
\hline \hline Recorder & Protection and threshold & $50 \mathrm{~ms}$ & $100 \mathrm{~ms}$ & $150 \mathrm{~ms}$ & $200 \mathrm{~ms}$ \\
\hline $\begin{array}{l}\text { duty } \\
\text { cycles }\end{array}$ & $27 D C / 0.2$ p.u. & 77.50 & 64.84 & 63.12 & 62.57 \\
\hline \hline
\end{tabular}

the DC filter (DCF) protection or the converter transformer protection;

The 3rd harmonic in the AC side may affect the AC Filter resistor (ACF) harmonic overload protection (time delay $5 \mathrm{~s}$ ), but the time delay is long enough.

\section{Conclusion on Co-ordination Between HVDC and HVAC}

The coordination between $\mathrm{AC}$ and $\mathrm{DC}$ protection should be clarified. Fllowing functions are influenced by $\mathrm{AC}$ fault, such as $87 \mathrm{CBY}, 87 \mathrm{CBD}, 87 \mathrm{CG}, 50 \mathrm{~Hz}, 100 \mathrm{~Hz}, 27 \mathrm{AC}, 27 \mathrm{DC}$. Time delay adjustment is the best way according to CSG AC backup protection time delays.

The characteristic of main equipment are studied that there is no negative influence to equipment with time delay of protection prolonged. The simulation tests were carried out by the RTDS based on 7 HVDC current projects, and the improved protection schemes were verified.

\section{Principle Analysis of AC Fault on DC Control AND PROTECTION}

\section{A. Similarities of Electrical Characteristics Between AC Faults and DC Faults}

The AC side faults can be divided into symmetric and asymmetric faults. When faults occur in an $\mathrm{AC}$ transmission line connected with HVDC station, commutation failure can happen leading to DC voltage collapse [16]. In the AC-DC hybrid system, the faults of the AC system will not only cause the transient response of the AC system, but also cause the transient process of the DC system.

Although the DC transient process caused by AC faults is different from that caused by DC faults, the main electrical characteristics of DC systems under AC faults are similar to those under DC faults. The main electrical characteristics of $\mathrm{AC}$ system faults on the rectifier side are low voltage and 100 $\mathrm{Hz}$ components. The main electrical characteristics of $\mathrm{AC}$ system faults on the inverter side are undervoltage, increased current, unbalanced current and $100 \mathrm{~Hz}$ components. These electrical characteristics are similar to some fault characteristics of DC systems.

The reasons for the $50 \mathrm{~Hz}$ component and $100 \mathrm{~Hz}$ component in DC are as follows: when an asymmetric fault occurs in the $\mathrm{AC}$ system, the fundamental frequency negative sequence voltage will result in $100 \mathrm{~Hz}$ component in both converter direct voltage and current. The second harmonic in transformer inrush may lead to the fundamental frequency component in HVDC system. AC transmission line parallel to DC transmission line induces $50 \mathrm{~Hz}$ voltage and $50 \mathrm{~Hz}$ current in DC line. The converter valve fault and the trigger system fault will lead to $50 \mathrm{~Hz}$ and $100 \mathrm{~Hz}$ current in DC. Continuous commutation failure can also result in $50 \mathrm{~Hz}$ and other harmonic currents.

The similarities of HVDC system electrical characteristics caused by AC faults and DC faults make it impossible for HVDC protection to distinguish AC faults from DC faults, which is the main reason for the maloperation of $\mathrm{DC}$ protection under AC fault.

\section{B. Imperfection of HVDC Protection Setting Methods}

There are many kinds of HVDC protection, and the main principle of protection is different in each zone. HVDC filter protection zone, HVDC bus zone and ground pole line zone are mainly protected by differential protections, which have good selectivity and are not affected by AC faults.

The converter zone generally adopts the differential protection as the main protections. The differential protection in the converter is based on the unbalance in internal faults which is balanced in normal operation. The imperfection of its criterion determines that it cannot guarantee absolute selectivity. As long as the monitoring current is not equal during the $\mathrm{AC}$ fault, the differential protection in the converter may mistrip. The converter zone uses some other protections as backup protections, such as $50 \mathrm{~Hz}$ detection, $\mathrm{AC}$ overcurrent 
protection, AC over/low voltage protection, DC over/low voltage protection. These protections cannot guarantee absolute selectivity in principle and the protection setting value has to been calculated accurately to avoid maloperation.

The main protection of HVDC line area is travelling wave protection and undervoltage protection, both of which are based on the principle of sudden change. During the HVDC transient process caused by AC fault on the inverter side, the sudden change of DC voltage and current may satisfy the criteria of travelling wave protection and undervoltage protection. Travelling wave protection and undervoltage protection both rely on setting value to avoid $\mathrm{AC}$ faults.

From the above analysis, it can be seen that the valve zone protection and line protection in the existing HVDC protection may mistrip during the AC fault in principle. The current DC protection setting methods, which mainly depend on manufacturers and simulation experiments, are not perfect. For example, some valve area protections with low settings or short delay, such as $87 \mathrm{CBY}, 87 \mathrm{CBD}, 87 \mathrm{CBY}, 87 \mathrm{CG}$, do not fully coordinate with $\mathrm{AC}$ protection. Although the line protection threshold can be set to avoid the most serious out-of-zone fault, the selectivity and sensitivity of line protection cannot be guaranteed when the fault characteristic of out-of-zone fault is close to that of zone fault.

HVDC protection may mistrip under AC fault due to the HVDC transient characteristic similarity of DC fault and AC fault and the imperfection of HVDC protection principle and setting method. The undervoltage characteristic of $\mathrm{AC}$ fault may cause the action of low voltage principle $\mathrm{DC}$ protection. Harmonic characteristics influence DC protection based on harmonic principle. The current imbalance makes the balance protection in the converter zone mistrip. The low voltage and high current characteristics of AC system on the inverter side may cause the maloperation of line protection.

Combined with real fault recorder data analysis and RTDS, it is concluded that $87 \mathrm{CBY}, 87 \mathrm{CBD}, 87 \mathrm{CG}, 27 \mathrm{AC}, 27 \mathrm{DC}, 50$ $\mathrm{Hz}$ detection and $100 \mathrm{~Hz}$ detection are susceptible when $\mathrm{AC}$ fault occurs. Therefore, only these five DC protection schemes need to be optimized.

\section{AC/DC Protection Coordination and Optimization SCHEMES}

\section{A. Principle of $A C$ and DC Protection Coordination}

\section{1) AC Faults Should be Removed by AC Protection}

Enhance AC protection:

Longitudinal differential protections are used on $220 \mathrm{kV}$ and above lines.

Optimize impedance protection setting, time delay of zone 2 (over-reach zone) is less than $2 \mathrm{~s}$.

Shorten time delay of BF (Breaker Failure) function of main stations to $160 \mathrm{~ms}$.

\section{2) DC Faults Should be Removed by DC Protection}

For each protection zone of HVDC, both main protection and backup protection are necessary.

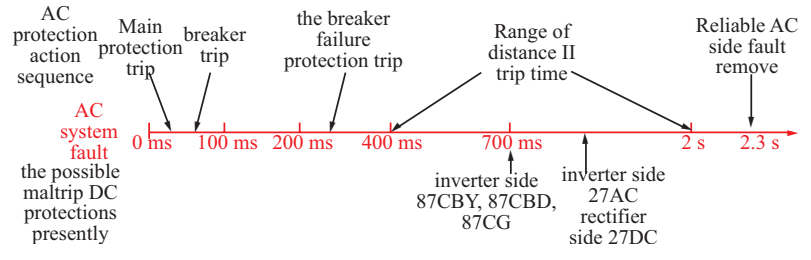

Fig. 6. The current AC and DC protection relationship.

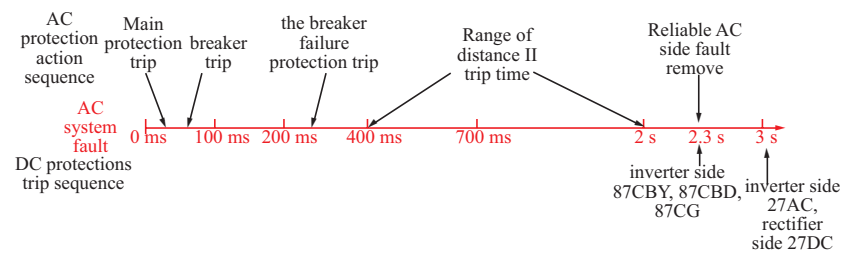

Fig. 7. The proposed AC and DC protection relationship.

Performance of some functions should co-ordinate with response time of related control function in pole control or the release time of breaker. For example, time delay of 82MRTB (metallic return transfer breaker protection) should co-ordinate with the course open/close of MRTB.

Up to now, no special problem.

\section{3) Protection Should Co-ordinate With Control in HVDC}

If over voltage or under voltage occurred in AC system, control function of HVDC should react faster than protection, transformer tap changer or ACF sub-bank switch on/off.

Performance of AC over current function (50/51C) should coordinate with over-load characteristic of pole control.

If large power transfers from DC to AC system, under voltage may occur on other stations, and $\mathrm{AC}$ protection maloperation may occur on some lines for over load.

\section{4) No HVDC Block During AC Fault}

\section{5) Keep the Rapid Action Characteristics of DC Protection}

\section{B. The Max AC Fault Time}

The longest possible time of the AC fault: 2.3 seconds, that is: "max backup protection time" + "breaker failure action time" + "breaker action time", in accordance with the setting calculation procedures:

Backup protection time: $2 \mathrm{~s}$. To ensure a sufficient sensitivity on metal fault in the line end, $500 \mathrm{kV}$ distance II time delay is not more than $2 \mathrm{~s}$;

Breaker failure action time: $0.2 \mathrm{~s}$;

Breaker action time: $0.1 \mathrm{~s}$.

Therefore, the current $\mathrm{AC}$ and $\mathrm{DC}$ protection relationship is shown in Fig. 6, the proposed $\mathrm{AC}$ and $\mathrm{DC}$ protection relationship is shown in Fig. 7.

\section{87CBY, 87CBD Protection Optimization Scheme}

87CBY, $87 \mathrm{CBD}$ protection optimization scheme is shown 
TABLE VI

87CBY, 87CBD PRoteCTION OPTIMIZATION SCHEME

\begin{tabular}{|c|c|c|c|c|c|}
\hline \multicolumn{2}{|c|}{ Protection } & Evaluation Principle & Old Setting (ms) & New Setting (ms) & Initiated Sequences \\
\hline \multirow{3}{*}{ 87CBY } & Stage 1 & $\max \left(I_{\mathrm{acY}} ; I_{\mathrm{acD}}\right)-I_{\mathrm{acY}}>0.4$ p.u. & 200 & - & current down to 0.3 p.u. \\
\hline & \multirow{2}{*}{ Stage 2} & $U_{\mathrm{ac}}>0.8$ p.u. $\& \max \left(I_{\mathrm{acY}} ; I_{\mathrm{acD}}\right)-I_{\mathrm{acY}}>0.1$ p.u. & 200 & - & block \\
\hline & & $U_{\mathrm{ac}}<0.8$ p.u. $\& \max \left(I_{\mathrm{acY}} ; I_{\mathrm{acD}}\right)-I_{\mathrm{acY}}>0.1$ p.u. & $700 / 800 / 1000$ & 2300 & block \\
\hline \multirow{3}{*}{ 87CBD } & Stage 1 & $\max \left(I_{\mathrm{acY}} ; I_{\mathrm{acD}}\right)-I_{\mathrm{acD}}>0.4$ p.u. & 200 & - & current down to 0.3 p.u. \\
\hline & \multirow{2}{*}{ Stage 2} & $U_{\mathrm{ac}}>0.8$ p.u. $\& \max \left(I_{\mathrm{ac}} ; I_{\mathrm{acD}}\right)-I_{\mathrm{acD}}>0.1$ p.u. & 200 & - & block \\
\hline & & $U_{\mathrm{ac}}<0.8$ p.u. $\& \max \left(I_{\mathrm{ac}} ; I_{\mathrm{acD}}\right)-I_{\mathrm{acD}}>0.1$ p.u. & $700 / 800 / 1000$ & 2300 & block \\
\hline
\end{tabular}

TABLE VII

87CG Protection ScheMe

\begin{tabular}{llccc}
\hline \hline & \multicolumn{1}{c}{ Evaluation Principle } & Old Setting $(\mathrm{ms})$ & New Setting $(\mathrm{ms})$ & \multicolumn{2}{c}{ Initiated Sequences } \\
\hline \multirow{2}{*}{ Stage 1} & $U_{\mathrm{ac}}>0.8$ p.u. \& $\min \left(I_{\mathrm{dCH}} ; I_{\mathrm{dCN}}\right)-\max \left(I_{\mathrm{acY}} ; I_{\mathrm{acD}}\right)>0.1$ p.u. & 200 & - & block \\
& $U_{\mathrm{ac}}<0.8$ p.u. \& $\min \left(I_{\mathrm{dCH}} ; I_{\mathrm{dCN}}\right)-\max \left(I_{\mathrm{ac}} ; I_{\mathrm{acD}}\right)>0.1$ p.u. & $700 / 800$ & 2300 & block \\
Stage 2 & $\min \left(I_{\mathrm{dCH}} ; I_{\mathrm{dCN}}\right)-\max \left(I_{\mathrm{ac}} ; I_{\mathrm{acD}}\right)>0.4$ p.u. & 40 & - & block \\
\hline \hline
\end{tabular}

in Table VI. Stage 1 and Stage 2 (Time delay 1) must react on continuous commutation failures for high load conditions. Delay time must be longer than redundancy switchover of pole control (200 ms);

Stage 2 (Time delay 2) must react on continuous commutation failures for low load conditions, not react on AC faults. Delay time must be longer than back-up clearing time of $\mathrm{AC}$ faults $(2.3 \mathrm{~s})$.

The delay time of $87 \mathrm{CBY} / \mathrm{D}$ Stage 2 is extended to $2.3 \mathrm{~s}$ (time delay setting of impedance protection zone 2, over-reach zone, is less than $2 \mathrm{~s}$ ).

\section{87CG Protection Optimization Scheme}

$87 \mathrm{CG}$ protection optimization scheme is shown in Table VII. Stage 1 and Stage 2 (Time delay 1) must react on converter DC faults that are bypassing the inverter in high load conditions. Delay time must be longer than redundancy switchover in Pole Control (200 ms); Stage 2 (Time delay 2) must not react on AC faults so the delay time must be longer than back-up clearing time of AC faults $(2.3 \mathrm{~s})$.

The delay time of $87 \mathrm{CG}$ Stage 2 is extended to $2.3 \mathrm{~s}$ (time delay setting of impedance protection zone 2, over-reach zone, is less than $2 \mathrm{~s}$ ).

\section{E. 27AC Protection Optimization Scheme}

$27 \mathrm{AC}$ protection is more of a system back-up function than protection of converter equipment. 27AC must react on low voltage characteristics caused by AC fault. Time delay must be longer than back-up clearing time of AC faults $(2.3 \mathrm{~s})$.

Improvement scheme: The time delay of $27 \mathrm{AC}$ is extended to $4 \mathrm{~s}$, threshold is also raised to $0.5 \mathrm{p} . \mathrm{u}$.

\section{F. 27DC Protection Optimization Scheme}

27DC protection is more of a system back-up function than protection of converter equipment, 27DC must react on low voltage characteristics caused by AC fault. Time delay must be longer than Back-up Clearing time of AC faults (2.3 s).

Improvement scheme: (a) Time delay is modified from $1 \mathrm{~s}$ to $2.3 \mathrm{~s}$; (b) DC low voltage monitoring function is added in the rectifier pole control which uses 27DC algorithm with time delay $1 \mathrm{~s}$ and is put into use when communication between stations is failure.

\section{G. $50 \mathrm{~Hz}$ Detection Optimization Scheme}

$50 \mathrm{~Hz}$ detection must react on continuous commutation failures or continuous misfire. Time delay stage 1 (current reduction 0.25 p.u.) is extended to $3 \mathrm{~s}$. Time delay stage 2 (block) is extended to $5 \mathrm{~s}$.

To avoid the $50 \mathrm{~Hz}$ detection mistrip, the three-phase shortcircuit current of AC bus in Niuzhai station should no less than $11.1 \mathrm{kA}$ when the (converter) transformers in Xiluodu power plant or Niuzhai station are energized.

\section{Optmization Scheme Impact Analysis}

\section{A. Protection Configuration Analysis in Case of DC Fault}

The protections that may be affected by AC fault are backup protections from the previous analysis. According to the DC protection configuration, these backup protections have corresponding fast protections as the main protection, so these backup protections can be optimized.

Valve short circuit protection (87CSY/87CSD) or converter over current protection $(50 / 51 \mathrm{C})$ can isolate the valve short circuits fault or valve ground fault quickly.

87CSY: Y side $I_{\mathrm{acY}-\mathrm{min}}\left(I_{\mathrm{dH}}-I_{\mathrm{dN}}\right)>\Delta$;

87CSY: D side $I_{\mathrm{acD}-\min }\left(I_{\mathrm{dH}}-I_{\mathrm{dN}}\right)>\Delta ; t_{1}=0 \mathrm{~ms}$;

$50 / 51 \mathrm{C}: I_{\mathrm{ac}}>\Delta, t_{1}=2 \mathrm{~ms}$. 
TABLE VIII

Current Tolerances Capacity of the Chusut HVDC Converter Valve

\begin{tabular}{|c|c|}
\hline & Value \\
\hline Rated DC current/A & 3125 \\
\hline Long term overload DC current $\left(P_{\mathrm{dc}}=1.1\right.$ p.u. $) / \mathrm{A}$ (maximum outdoor ambient temperature) & 3461 \\
\hline $2 \mathrm{~h}$ overload DC current $\left(P_{\mathrm{dc}}=1.1\right.$ p.u. $) / \mathrm{A}($ maximum outdoor ambient temperature $)$ & 3461 \\
\hline $3 \mathrm{~s}$ overload DC current $\left(P_{\mathrm{dc}}=1.4\right.$ p.u. $) / \mathrm{A}$ (maximum outdoor ambient temperature) & 4539 \\
\hline Valve short circuit current (Maximum short circuit capacity)/kA & $\leq 33$ \\
\hline Maximum cycle number before circuit breaker opening & 3 \\
\hline Recovery voltage after valve short circuit current/p.u. & $\leq 1.10$ \\
\hline Valve short circuit current (Maximum short circuit capacity)/kA & $\leq 25$ \\
\hline Maximum cycle number before circuit breaker opening & 3 \\
\hline Recovery voltage after valve short circuit current/p.u. & $\leq 1.30$ \\
\hline
\end{tabular}

TABLE IX

Calculation Results of Valve Current in the Inverter Side of the Chusu HVDC WITH AC FAULT

\begin{tabular}{lccc}
\hline \hline case & case description & $\begin{array}{c}\text { Valve current } \\
\text { Maximum value } \\
\text { p.u. }\end{array}$ & $\begin{array}{c}\text { Valve current } \\
\text { over } 1.5 \text { p.u. } \\
\text { time } / \mathrm{ms}\end{array}$ \\
\hline 1 & $P_{2}=1.0$ p.u., $F_{1}=0 \%, \max$ & 2.137 & 36 \\
8 & $P_{2}=0.4$ p.u., $F_{1}=0 \%, \max$ & 1.64 & 23 \\
9 & $P_{2}=1.2$ p.u., $F_{1}=20 \%, \max$ & 2.46 & $39+8=47$ \\
12 & $P_{2}=1.2$ p.u., $F_{1}=60 \%, \max$ & 2.03 & 36 \\
13 & $P_{2}=1.2$ p.u., $F_{1}=55 \%, \max$ & 2.6 & 40 \\
15 & $P_{1}=1.2$ p.u., $F_{1}=20 \% \max$ & 2.008 & 93 \\
\hline \hline
\end{tabular}

87CBY/87CBD stage $1,87 \mathrm{CG}$ stage 1 can isolate the valve short circuits fault or valve ground fault as backup functions.

87CBY,87CBD,87CG have an auxiliary criterion based on AC voltage:

$U_{\text {ac }}>0.8$ p.u. , delay time $200 \mathrm{~ms}$.

$U_{\text {ac }}<0.8$ p.u. , delay time $700 / 800 / 1000 \mathrm{~ms}$.

\section{B. Main Equipment Characteristics Verification}

On the one hand, the optimization scheme is coordinated with $\mathrm{AC}$ protection and DC control system. On the other hand, it must be coordinated with the tolerances of the DC main equipment, like valve, convertor transformer, ACF resistor, et al.

For example, valve tolerances, which is low usually, must be checked because valve is the most expensive equipment in converter station.

\section{1) Verification of Valve Maximum Short Circuit Duration}

Overcurrent: The voltage dependent current order limiter (VDCOL) reduces DC current quickly $(10 \mathrm{~ms})$ for commutation failures; $87 \mathrm{CSY} / 87 \mathrm{CSD}$ can isolate the valve short circuits fault or valve ground fault quickly.

In order to verify whether $87 \mathrm{CSY} / 87 \mathrm{CSD}$ trip of the converter will occur in the case of AC failure, the following RTDS analysis and calculation are carried out.

Tolerances of Chu-sui HVDC converter valve is shown in Table VIII.
EMTDC simulation configuration: The AC faults are set in the inverter station high voltage $\mathrm{AC}$ bus, DC protections trip and pole control ESOF are disabled. The calculation results are shown in Table IX.

$P_{1}$ is the HVDC power in monopole earth mode, $P_{1 \mathrm{M}}$ is the HVDC power in monopole metal mode, $P_{2}$ is the bipole HVDC power in bipole earth mode. $F_{1}$ is the single-phase ground fault in the inverter station high voltage $\mathrm{AC}$ bus, $F_{3}$ is the three-phase ground fault in the inverter station high voltage AC bus. $F_{1}$ and $F_{3}$ both last for 5 seconds.

Max represents the maximum short-circuit capacity, min represents the minimum short-circuit capacity. The $\%$ represents the remaining $\mathrm{AC}$ voltage compared with the original voltage in case of fault.

The typical calculation results are shown in Table IX. The maximum valve current is 2.6 p.u. (case 13), and the maximum time where the valve current is over 1.5 p.u. is $93 \mathrm{~ms}$ (condition 15). During the fault process, the HVDC current limiting function makes the DC current drop rapidly so that the $87 \mathrm{CSY} / 87 \mathrm{CSD}$ would not trip.

The optimization scheme is combined with the practical operation experience and fully coordinated with the equipment tolerance. As confirmed by the valve manufacturer, valve will not be damaged unless short circuit protection (87CSY, 87CSD) settings are modified. The optimization scheme don't change the $87 \mathrm{CSY}$, 87CSD settings so that valve stresses (maximum short circuit duration) is tolerable.

Valve: Intermittent current of valve will cause snubber circuit overload within a few seconds. The valves are designed to withstand $600 \mathrm{~Hz}$ intermittent current for $1 \mathrm{~s}$. The EMTDC simulation results and practical engineering experiences show that the valve current discontinuity will not occur on various $\mathrm{AC}$ system faults, and the trigger angle will not remain in a large angle range for a long time.

High temperature protection (delay time $20 \mathrm{~s}$ ) is used to monitor the temperature of the converter valve; Big rigger angle monitor (delay time $10 \mathrm{~s}$ ) in pole control is used as a backup protection for monitoring the operation condition of valve. 
TABLE X

Fault Point 1 87CBY (CBD), 87CG, 27AC Test Items

\begin{tabular}{|c|c|c|c|c|}
\hline No & Test description & $\begin{array}{l}\text { HVDC converter } \\
\text { station }\end{array}$ & $\begin{array}{l}\text { Communication between } \\
\text { stations }\end{array}$ & System operation mode \\
\hline 1.1 & $\begin{array}{l}\text { Pole } 1 \text { ground return } 1500 / 1600 \mathrm{MW}, \mathrm{AC} \text { A phase to ground } \\
\text { fault, } 0 \%, 5000 \mathrm{~ms}\end{array}$ & Rectifier Side & Normal & Equivalent large system \\
\hline 1.2 & $\begin{array}{l}\text { Pole } 1 \text { ground return } 1500 / 1600 \mathrm{MW} \text {, AC A phase to ground } \\
\text { fault, } 70 \%, 5000 \mathrm{~ms}\end{array}$ & Rectifier Side & Normal & Equivalent large system \\
\hline 1.3 & $\begin{array}{l}\text { Pole } 1 \text { ground return } 1500 / 1600 \mathrm{MW}, \mathrm{AC} \mathrm{AB} \text { phases to } \\
\text { ground fault, } 0 \%, 5000 \mathrm{~ms}\end{array}$ & Rectifier Side & Normal & Equivalent large system \\
\hline 1.4 & $\begin{array}{l}\text { Pole } 1 \text { ground return } 1500 / 1600 \mathrm{MW}, \mathrm{AC} \mathrm{AB} \text { phases short } \\
\text { circuit fault, } 0 \%, 5000 \mathrm{~ms}\end{array}$ & Rectifier Side & Normal & Equivalent large system \\
\hline 1.5 & $\begin{array}{l}\text { Pole } 1 \text { ground return } 1500 / 1600 \mathrm{MW}, \mathrm{AC} \mathrm{ABC} \text { three phases } \\
\text { short circuit fault, } 0 \%, 5000 \mathrm{~ms}\end{array}$ & Rectifier Side & Normal & Equivalent large system \\
\hline 1.6 & $\begin{array}{l}\text { Pole } 1 \text { ground return } 1500 / 1600 \mathrm{MW}, \mathrm{AC} \text { A phase to ground } \\
\text { fault, } 0 \%, 5000 \mathrm{~ms}\end{array}$ & Inverter side & Normal & Equivalent large system \\
\hline 1.7 & $\begin{array}{l}\text { Pole } 1 \text { ground return } 1500 / 1600 \mathrm{MW} \text {, AC A phase to ground } \\
\text { fault, } 70 \%, 5000 \mathrm{~ms}\end{array}$ & Inverter side & Normal & Equivalent large system \\
\hline 1.8 & $\begin{array}{l}\text { Pole } 1 \text { ground return } 1500 / 1600 \mathrm{MW}, \mathrm{AC} \mathrm{AB} \text { phases to } \\
\text { ground fault, } 0 \%, 5000 \mathrm{~ms}\end{array}$ & Inverter side & Normal & Equivalent large system \\
\hline 1.9 & $\begin{array}{l}\text { Pole } 1 \text { ground return } 1500 / 1600 \mathrm{MW}, \mathrm{AC} \mathrm{AB} \text { phases short } \\
\text { circuit fault, } 0 \%, 5000 \mathrm{~ms}\end{array}$ & Inverter side & Normal & Equivalent large system \\
\hline 1.10 & $\begin{array}{l}\text { Pole } 1 \text { ground return } 1500 / 1600 \mathrm{MW}, \mathrm{AC} \mathrm{ABC} \text { three phases } \\
\text { short circuit fault, } 0 \%, 5000 \mathrm{~ms}\end{array}$ & Inverter side & Normal & Equivalent large system \\
\hline 1.11 & $\begin{array}{l}\text { Pole } 1 \text { ground return } 1500 / 1600 \mathrm{MW} \text {, AC A phase to ground } \\
\text { fault, } 30 \%, 5000 \mathrm{~ms}\end{array}$ & Rectifier Side & Normal & Typical system \\
\hline 1.12 & $\begin{array}{l}\text { Pole } 1 \text { ground return } 1500 / 1600 \mathrm{MW}, \mathrm{AC} \mathrm{ABC} \text { three phases } \\
\text { short circuit fault, } 30 \%, 5000 \mathrm{~ms}\end{array}$ & Rectifier Side & Normal & Typical system \\
\hline 1.13 & $\begin{array}{l}\text { Pole } 1 \text { ground return } 1500 / 1600 \mathrm{MW}, \mathrm{AC} \text { A phase to ground } \\
\text { fault, } 30 \%, 5000 \mathrm{~ms}\end{array}$ & Inverter side & Normal & Typical system \\
\hline 1.14 & $\begin{array}{l}\text { Pole } 1 \text { ground return } 1500 / 1600 \mathrm{MW}, \mathrm{AC} \mathrm{ABC} \text { three phases } \\
\text { short circuit fault, } 30 \%, 5000 \mathrm{~ms}\end{array}$ & Inverter side & Normal & Typical system \\
\hline
\end{tabular}

\section{2) The Tolerances of Other Main Equipment}

a) Converter transformer: The transformer overcurrent setting is 1.2 rated load current for $3 \mathrm{~s}$, which is lower than the transformer overload capability (1.2 p.u. for 2 hours) or the HVDC overload capability (1.2 p.u. for 2 hours).

When there is an AC system asymmetrical fault, the current in the delta winding of the YD transformer is very large due to the zero sequence voltage. However, the safety of the converter transformer will not be threatened because the transformer can withstand inrush which may greater than $8 \mathrm{kA}$.

b) Reactor: The reactor heating time constant is over $1000 \mathrm{~s}$ for rated $600 \mathrm{~Hz}$ current. Therefore, the failure of about $3 \mathrm{~s}$ will not lead to the overheating of the reactor.

c) Neutral bus arrester and DCF: The EMTDC calculation shows that the stress on the neutral bus arrester is significant only during a long period of commutation failure.

d) DCF: The EMTDC results show that, the voltage and current of the 2nd harmonic don't increase much under the AC asymmetric fault, so DCF will not be affected by the short-time overload.

e) ACF: ACF reactor has a very strong overload capacity and is not a bottleneck factor. The main consideration is the resistor heat capacity, which is limited by the $\mathrm{AC}$ asymmetric fault type, especially resistors in the triple tuned filter. This is caused by the significant increase of the 3 rd harmonic current when an asymmetric fault occurs in the AC system.

However, the overload capacity of filter resistors is different in each HVDC. The resistors overload capacity of the ACF in most HVDC are large (> 10MJ) and can withstand AC system failures for a long time, which are proved by EMTDC simulation. But the heat capacity of the triple tuned filter resistors on Tian-Guang HVDC and Niu-Cong HVDC are small, which cannot withstand the harmonics under long-time $\mathrm{AC}$ asymmetric failure. The resistor heat capacities in some ACF were improved in these converter stations.

The characteristic of ACF resistor/reactor thermal overload protections is also changed from definite time to inverse overcurrent-time, for full use of the ACF resistor/reactor tolerances.

The amount of protections devices, adopting the above inverse overcurrent-time protection, is as below: 38 in Luxi converter station, 84 in Niu-Cong HVDC, 48 in Jing-Zhong HVDC, 62 in Yong-Fu HVDC, 64 in Pu-Qiao HVDC.

So the optimized scheme is feasible when the tolerances of the main equipment are all checked.

\section{RTDS SimULATion Verification}

118 experiments have been carried out on the 7 HVDC RTDS platforms with the above optimization scheme adopted, when the different operating conditions of AC and DC systems are taken into account.

The modification scheme validity of HVDC protection settings in Tian-guang, Gui-guang 1, Gui-guang 2, Chu-sui, $\mathrm{Pu}$-qiao, Niu-cong HVDC projects is verified by RTDS results of typical faults at $\mathrm{AC}$ and $\mathrm{DC}$ sides. 
TABLE XI

Other Fault Point 87CBY (CBD), 87CG Test Items

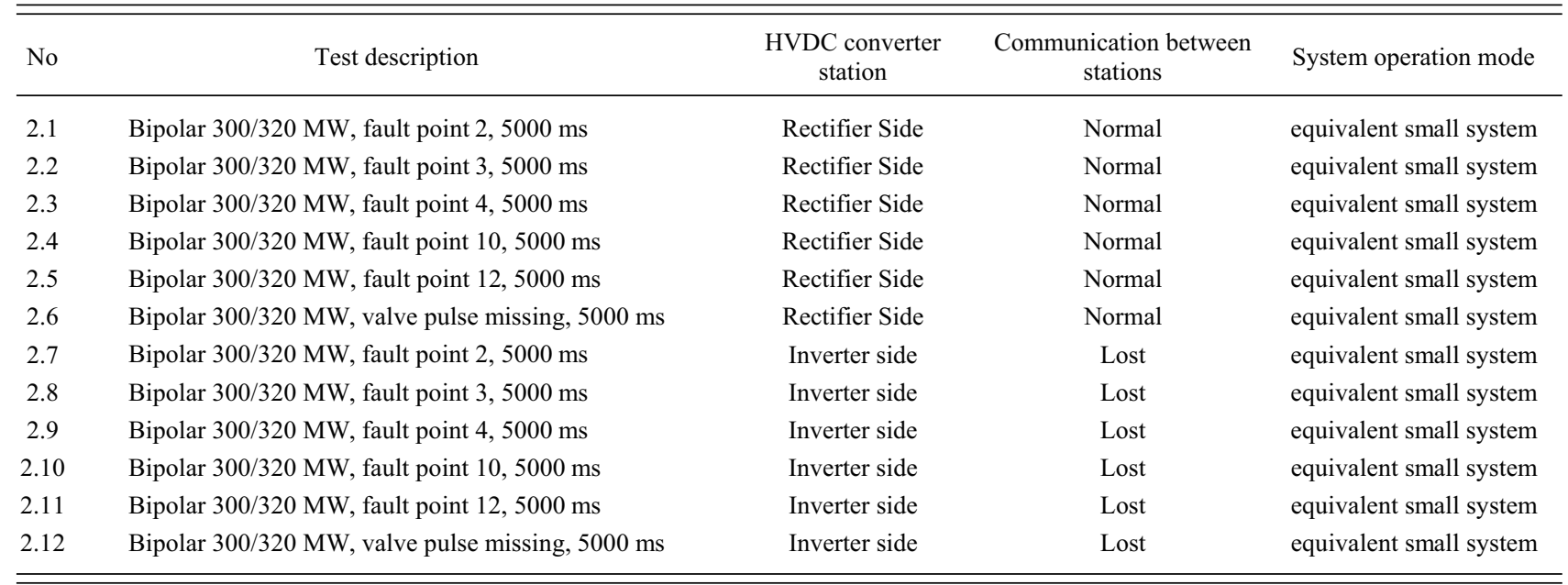

The test items include: HVDC protections do not mistrip with AC fault at fault point 1, as shown in Table X; when DC fault occurs, main protection action correctly, as shown in Table XI.

The simulation results show that:

- 87CBY/D, 87CG, 27AC, $50 \mathrm{~Hz}$ and 27DC protections will not trip when $\mathrm{AC}$ fault (5 s) occurs at the grid side;

- In DC fault and valve pulse lost simulation test, the DC main protections trip correctly. 87CBY (CBD), 87CG, 27AC, $50 \mathrm{~Hz}$ and 27DC protections did not trip;

-When the communication between stations is normal, the DC low-voltage monitoring function at the rectifier side does not trip correctly under various fault conditions; When the communication between stations is lost and the DC voltage is continuously lower than the threshold value, the DC low-voltage monitoring function at the rectifier side will operate $1 \mathrm{~s}$ later.

The RTDS results show that the optimization scheme can be implemented on site.

\section{Conclusion}

In order to prevent the multi HVDC systems power reducing or blocking at the same time due to $\mathrm{AC}$ fault, this paper studies and formulates $\mathrm{AC} / \mathrm{DC}$ protection cooperation principles: the AC system side fault should be removed by AC protections as much as possible; the DC system should maintain operation when $\mathrm{AC}$ system fault is cleared by $\mathrm{AC}$ protections.

According to this principle, the $\mathrm{DC}$ control and protection functions that may trip under $\mathrm{AC}$ fault are studied completely. Combined with AC protection and DC control analysis, action sequence research, digital simulation and other research methods, the optimization ideas and schemes of 12 HVDC protections are formulated. The optimization scheme is based on the available tolerances of DC equipment which are verified clearly. Finally, 118 RTDS tests have been carried out on the 7 HVDC RTDS platforms with the above optimization scheme adopted. Operation experience shows that the research results can effectively avoid the risk of multiple HVDC power reduction or blocking caused by serious AC fault. The optimized schemes have been implemented and applied in China South Grid since 2017.

\section{REFERENCES}

[1] S. Lin, J. Liu, L. Liu, Y. Lei, and C. Fu, "A review of commutation failure suppression methods for HVDC systems based on control protection measures," in Proceedings of the CSEE, vol. 40, no. 19, pp. 6046-6048, Oct. 2020.

[2] C. Zheng, S. Ma, X. Shen, and D. Liu, "Definition, connotation and form of strong HVDC and AC and weak counter measures for stable operation of hybrid power grid," in Power System Technology, vol. 41, no. 8, pp. 2491-2498, Aug. 2017.

[3] B. Gao, R. Zhang, and X. Zhang, "A novel procedure for protection setting in an HVDC system based on fault quantities," in Journal of Electrical Engineering \& Technology, vol. 12, no. 2, pp. 513-521, Mar. 2017.

[4] J. Zhao, S. Cao, T. Liu, and A. Zhang, "Research and optimization on DC line fault recovery strategy used in Gui-Guang HVDC project," in Power System Protection and Control, vol. 38, no. 23, pp. 126-132, Dec. 2010.

[5] B. Wang, Z. Li, Z. Bai, P. T. Krein, and H. Ma, "Real-time diagnosis of multiple transistor open circuit faults in a T-type inverter based on finite state machine model," in CPSS Transactions on Power Electronics and Applications, vol. 5, no. 1, pp. 74-85, Mar. 2020.

[6] China Southern Power Grid Ultrahigh Voltage Transmission Company Group, "Typical fault analysis and field treatment of $\pm 800 \mathrm{kV}$ cloud-wide UHVDC transmission system," Beijing, China: China Electric Power Press, 2016, pp. 7-11.

[7] W. Chen, E. Hotchkiss, and A. Bazzi, "Reconfiguration of NPC multilevel inverters to mitigate short circuit faults using back-to-back switches," in CPSS Transactions on Power Electronics and Applications, vol. 3, no. 1, pp. 46-55, Mar. 2018.

[8] X. Lin, Y. Xiang, and J. Quan, "Simulation analysis of convert transformer DC-biasing under HVDC system in ground return operation," in Journal of Electric Power Science and Technology, vol. 28, no. 1, pp. 31-35, Mar. 2013.

[9] J. Duan, Y. Wan, and W. Lu, "Research on transient-based boundary protection for HVDC transmission lines," in Journal of Electric Power Science and Technology, vol. 28, no. 2, pp. 22-27, Jun. 2013.

[10] X. Chen, L. Huang, P. Fu, G. Gao, Z. Song, L. Xu, S. He, and X. Hang, "System realization of CASHIPS DC high power test facility," in CPSS Transactions on Power Electronics and Applications, vol. 4, no. 2, pp. 101-108, Jun. 2019 
[11] J. He, B. Li, Y. Li, H. Qiu, C. Wang, and D. Dai, "A fast directional pilot protection scheme for the MMC-based MTDC grid," in Proceedings of the CSEE, vol. 37, no. 23, pp. 6878-6887, 7078, Mar. 2017.

[12] J. Liu, N. Tai, C. Fan, S. Chen, and J. Chen, "A fault identification method for HVDC transmission lines based on transient measured impedance," in Proceedings of the CSEE, vol. 36, no. 20, pp. 5504-5514, Jun. 2016.

[13] X. Kong, Y. Yuan, L. Gao, P. Li, and J. Lin. "Study of distance protection scheme for transmission line including UPFC," in Proceedings of the CSEE, vol. 36, no. 19, pp. 5219-5226, Sept. 2016.

[14] N. Huang, C. Fan, and S. Jiang, "Coordination method between AC and DC protections based on DC side $100 \mathrm{~Hz}$ component," in Power System Technology, vol. 43, no. 11, pp. 4150-4159, Nov. 2019.

[15] S. Luo, "Research on relay protection of HVDC transmission lines," $\mathrm{Ph} . \mathrm{D}$. dissertation, Tsinghua University, Beijing, China, 2016.

[16] M. Muniappan, "A comprehensive review of DC fault protection methods in HVDC transmission systems," in Protection and Control of Modern Power Systems, vol. 6, no. 1, pp. 1-20, Jan. 2021.

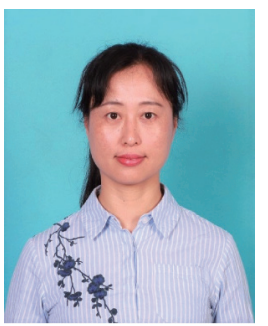

Yonghong Tao was born in 1976 in Anhui, China. She received her B.S. degree in power system and automation from Hefei University of Technology in 1998 and her M.S. degree from Xihua University in 2005. She has been a lecturer at the School of Electrical and Electronic Information, Xihua University since 2004. Her research interests include power system equipment and high voltage.

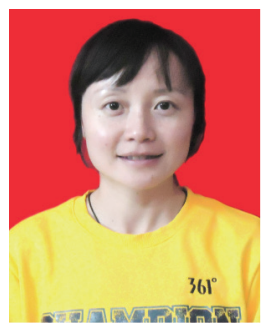

Xia Lei received her B.Sc. and M.Sc. degrees in electrical engineering from Sichuan University. She is currently a professor in the School of Electrical Engineering and Electronic Information at Xihua University. Her research fields are the optimal operation of electrical systems with renewable energy and power markets.

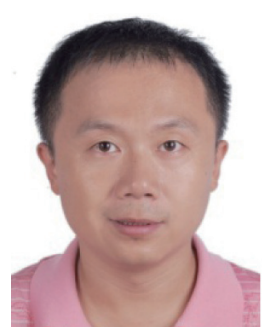

Qing Tian received the B.S. degree in power system and automation from Huazhong University of Science and Technology, in 1998 and the D.S. degree in 2006. He is currently working in Power Dispatching Center China Southern Power Grid. His research interests include operation and management of relay protection.

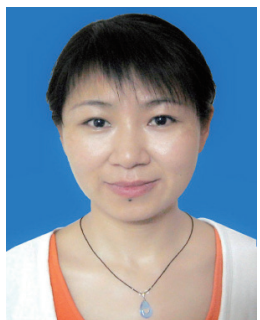

Huali Xu was born in Anhui province Huaibei city 1975, obtained degree of master of engineering in Hefei university of technology 2004. From 1994 to 1998, Undergraduate education, majored in Electrical System and Automation, Electrical Engineering Department, Hefei University of Technology; From 1998 to 2001, worked in high voltage system design in Suixi Power Supply Bureau. From 2001 to 2004 , Postgraduate Education, majored in Electrical System and Automation, School of Electrical, Hefei University of Technology; Since 2004, worked in power plant design in China United Engineering Co., Ltd. 